International Journal of Child and Adolescent Resilience

Revue internationale de la résilience des enfants et des adolescents

\title{
\#ChildMaltreatment and Technology
}

\section{Scottye J. Cash}

Volume 6, Number 1, 2019

URI: https://id.erudit.org/iderudit/1069075ar

DOI: https://doi.org/10.7202/1069075ar

See table of contents

Publisher(s)

Canada Research Chair in Interpersonal Traumas and Resilience/Chaire de recherche du Canada sur les traumas interpersonnels et la résilience

ISSN

2292-1761 (digital)

Explore this journal

Cite this article

Cash, S. (2019). \#ChildMaltreatment and Technology. International Journal of Child and Adolescent Resilience / Revue internationale de la résilience des enfants et des adolescents, 6(1), 45-51. https://doi.org/10.7202/1069075ar

\section{Article abstract}

Technology may seem like a friend one day, a foe another depending on how and why it is being used. In today's world, we are inundated with social media, smart phones, tvs, and cars. Our ability to harness technology to make our lives a better place is a noble goal, however our ability to harness technology to enhance our research skills is absolutely necessary. The current paper explores the ways in which technology has been used and can be used to better understand child maltreatment and domestic violence. Overall, the message is clear, integrating technology-based research methods and practical approaches to helping vulnerable populations is one of this generations' paradigm shifts. Technology coupled with sound research methodologies can help move us forward in our exploration and understanding of social problems and interventions.
All Rights Reserved @ Scottye J. Cash, 2019

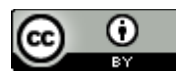

This document is protected by copyright law. Use of the services of Érudit (including reproduction) is subject to its terms and conditions, which can be viewed online.

https://apropos.erudit.org/en/users/policy-on-use/ 


\title{
International Journal of Child and Adolescent Resilience
}

\section{\#ChildMaltreatment and Technology}

\author{
Scottye J. Cash ${ }^{1}$
}

1 MSSW, Ph.D., Associate Professor, College of Social Work, The Ohio State University

\begin{abstract}
:
Technology may seem like a friend one day, a foe another depending on how and why it is being used. In today's world, we are inundated with social media, smart phones, tvs, and cars. Our ability to harness technology to make our lives a better place is a noble goal, however our ability to harness technology to enhance our research skills is absolutely necessary. The current paper explores the ways in which technology has been used and can be used to better understand child maltreatment and domestic violence. Overall, the message is clear, integrating technology-based research methods and practical approaches to helping vulnerable populations is one of this generations' paradigm shifts. Technology coupled with sound research methodologies can help move us forward in our exploration and understanding of social problems and interventions.
\end{abstract}

\section{Acknowledgements:}

My sincerest appreciation for Drs. Laura Schwab Reese and Tara Black for their comments and feedback on earlier versions.

\section{Funding Source:}

None.

\section{Conflict of Interest:}

The author has no conflicts of interest to disclose.

\section{Keywords:}

child maltreatment, social media, technology 
Krazenberg's First Law: “Technology is neither good nor bad; nor is it neutral...technology's interaction with the social ecology is such that technical developments frequently have environmental, social, and human consequences that go far beyond the immediate purposes of the technical devices and practices themselves, and the same technology can have quite different results when introduced into different contexts or under different circumstances"

(Kranzberg, 1986)

In 2018, the number of Internet users in the world surpassed four billion people, which indicates that more than half (53\%) of the world are online. Sixty-eight percent of the world (5.135 billion people) use a mobile device (e.g., smartphone, mobile phone) (wearesocial. com, 2018) and $42 \%$ percent ( 3.196 billion people) of the world actively use some form of social media. The term "social media" is used ubiquitously in cultures throughout the world, however there are very few agreed upon or theoretical definitions of social media. Based on Ouirdi and colleagues (2014) study, they developed the following theoretical definition of social media: "a set of mobile and web-based platforms built on Web 2.0 technologies, and allowing users at the micro-, meso- and macro- levels to share and geo-tag user-generated content (images, text, audio, video and games), to collaborate, and to build networks and communities, with the possibility of reaching and involving large audiences" (p.123). Based on their working definition of social media, the following platforms meet their criteria of what is considered social media: Facebook, Twitter, YouTube, Wikipedia, LinkedIn, Tumbler, ResearchGate, Academia. Each social media platform has unique opportunities and challenges for networking and research, however given the data on the number of users of social media and the potential benefits, social media can provide a communication space with great breadth where the public, government organizations, and social service agencies can come together to disseminate information and promote positive change at many levels.

Social media and social networking have taught us the importance of how content can be used to shape how we interact with environments of public and networked information (boyd, 2008). These "Networked publics are publics that are restructured networked technologies...they are simultaneously (1) the space constructed through networked technologies and (2) the imagined community that emerges as a result of the intersection of people, technology, and practice" (p.15).The established network publics have not only opened new opportunities for individuals, organizations, communities to find and disseminate information, but also for researchers who can maximize these platforms for data collection, recruitment, and dissemination.

boyd (2008) argues that data from social networking sites has the following aspects, which are key to the definition of networked publics: "Persistence: online expressions are automatically recorded and archived; Replicability: content made out of bits can be duplicated; Scalability: the potential visibility of content in networked publics is great; and Searchability: content in networked publics can be accessed through search (p.27). These key aspects are what create the opportunities for social networking to be a data source that can be used by researchers to answer a multitude of research questions. While social networking was not originally designed to serve as a source of data, as Kranzenburg's (1986) First Law 
states, "technology can have quite different results when introduced into different contexts or under different circumstances." His argument also holds true that social networking data provide us with the opportunity to examine the "environmental, social, and human consequences" (p.2).

The ability to harness these massive communication platforms presents both challenges and opportunities for conducting research and translating research into meaningful findings for key stakeholders. Collecting accurate and dynamic data in child maltreatment is dependent upon a multitude of factors at different levels of the system (e.g., child, perpetrator, mandated reports, child welfare system, and technology capabilities). Some of the factors that can impede data collection include the varying definitions of child maltreatment across jurisdictions, ability to access accurate reports of all instances of child maltreatment occurrences/recurrences, access to individuals who reported the data or who have first-hand knowledge of the situation, willingness and ability of victims and perpetrators to accurately report the event(s), social desirability, technology infrastructure to capture all of the dynamics of the maltreatment, and sharing of data across jurisdictions (Schwab-Reese, Hovdestad, Tonmyr, \& Fluke, 2018). Given the multi-systemic challenges of collecting child welfare data combined with the exciting advances in technology and mining large datasets, child welfare researchers are looking at the role technology and social media can play in advancing our knowledge of and work with child maltreatment.

As noted above, Schwab-Reese et al., (2018) scoping review identifies the challenges associated with collecting child maltreatment surveillance data; however, they extend the discussion to demonstrate how social media and technology can be used to support our understanding of child maltreatment. Their review found that most of the research methods have been used in medicine and health related fields, but most can be adapted to increase our ability to understand child maltreatment from an epidemiological approach. These ideas include crowdsourcing, online recruiting, Internet search query, and media reports. Social media platforms, such as Twitter and Facebook, may also be possible to include. Ideally, they suggest that a combination of approaches should be used and can facilitate triangulation of methods to best understand.

The review by Schwab-Reese et al., (2018) prompted me to conduct two analyses to understand how Facebook, Google Trends ("Google Trends," 2018) and Twitter data can be used to understand child maltreatment. Facebook has recently been in the news with the data breach with Cambridge Analytica, which has generated significant negative attention on its platform and services (Griffiths, 2018; Timberg, Romm, \& Dwoskin, 2018). When I accessed the Facebook development platform, it has recently changed its policies and is currently not allowing outside developers to gain access to Facebook user data (Archibong, 2018).

Google Trends uses an intuitive process to collect data on keywords and how they have trended in the past. For this analysis (see Figure 1), I entered the keywords "child abuse," "child neglect," "sexual abuse," and "child maltreatment," selected the United States, and requested data on trends for the previous 12 months (April 9, 2017 to April 1, 2018). The $\mathrm{x}$-axis represents the weeks and the $\mathrm{y}$-axis is the Interest Over Time, which is "Numbers 
represent search interest relative to the highest point on the chart for the given region and time. A value of 100 is the peak popularity for the term. A value of 50 means that the term is half as popular. A score of 0 means there was not enough data for this term." The results show that "child abuse" was the most searched term, while "child maltreatment" was the least. The highest interest levels were in April, which coincidentally is National Child Abuse Prevention month, which would provide one explanation as to why "child abuse" would be a high frequency search term. Week 38 (12/23/17) showed a significant drop in interest for both child abuse and sexual abuse. The exact reason for this is unknown, however it may be due to the proximity to winter holidays. Two weeks later, January 14, 2018, there was another spike in searches for "child abuse," "sexual abuse," and "child neglect," while "child maltreatment" searches remained consistently low. Google Trends could be used to understand trends and try to pinpoint any events could have influenced interest on social media and the Internet.

Accessing historical data from Twitter initially proved to be challenging and expensive. However, after exploring numerous options suggested from a research on ResearchGate, I found TAGS, a Twitter Archiving Google Sheet. TAGS v.6.1.8 is a "free Google Sheet template which lets you setup and run automated collection results from Twitter" (Hawksey, 2018). The google docs interface allows users to identify Twitter search terms and collect up to 3,000 tweets (Twitter Terms of Service limit) over a one-week period. There is an option to update the archive to obtain new tweets that match the search term every hour. The following hashtag terms (without spaces) were entered into the TAGS program "childabuse," "childneglect," "sexualabuse," and "childmaltreatment." "ChildAbuse" had the most unduplicated tweets, with 2,815; "ChildNeglect" had 23, "SexualAbuse" had 1,879, and "ChildMaltreatment" had zero. Given the focus of the article by Wekerle et al., (2018), I ran an analysis of "CIHRTeamSV" and found six tweets in the last week that highlighted recent research shared using this hashtag. The TAGS program also archives the individual tweets and designates if the tweet is a retweet or original tweet. These data from Twitter could be analyzed, at a minimum, using a qualitative analytical method, such as content analysis (Figure 1).

While social media and other technology-facilitated approaches to data collection may be used for epidemiological research, it is imperative that the research findings be translated to practitioners, clients, policy makers, and other researchers. The National Institutes of Health Bench-to-Bedside program encourages scholars to create practical applications of their research ("NIH Clinical Center: NIH Bench-to-Bedside Program," 2018). While the Bench-to-Bedside program has typically focused primarily on moving research from laboratory settings to patient care, the tenets hold true for social science research as well, that dissemination of findings is critical to improve understanding of client needs and providing evidence-based services. Wekerle et al., (2018) explored the use of Twitter (\#CIHRTeamSV) and ResearchGate to increase visibility of research on sexual violence prevention. They found that using Twitter and ResearchGate did increase engagement in scholarly activities and dissemination of findings.

Technology-facilitated approaches may also be used to directly work with children and young people impacted by child maltreatment. Research on the relationship between social 
Figure 1: Google Trends Child Welfare Related Topics (April 2017 - April 2018)

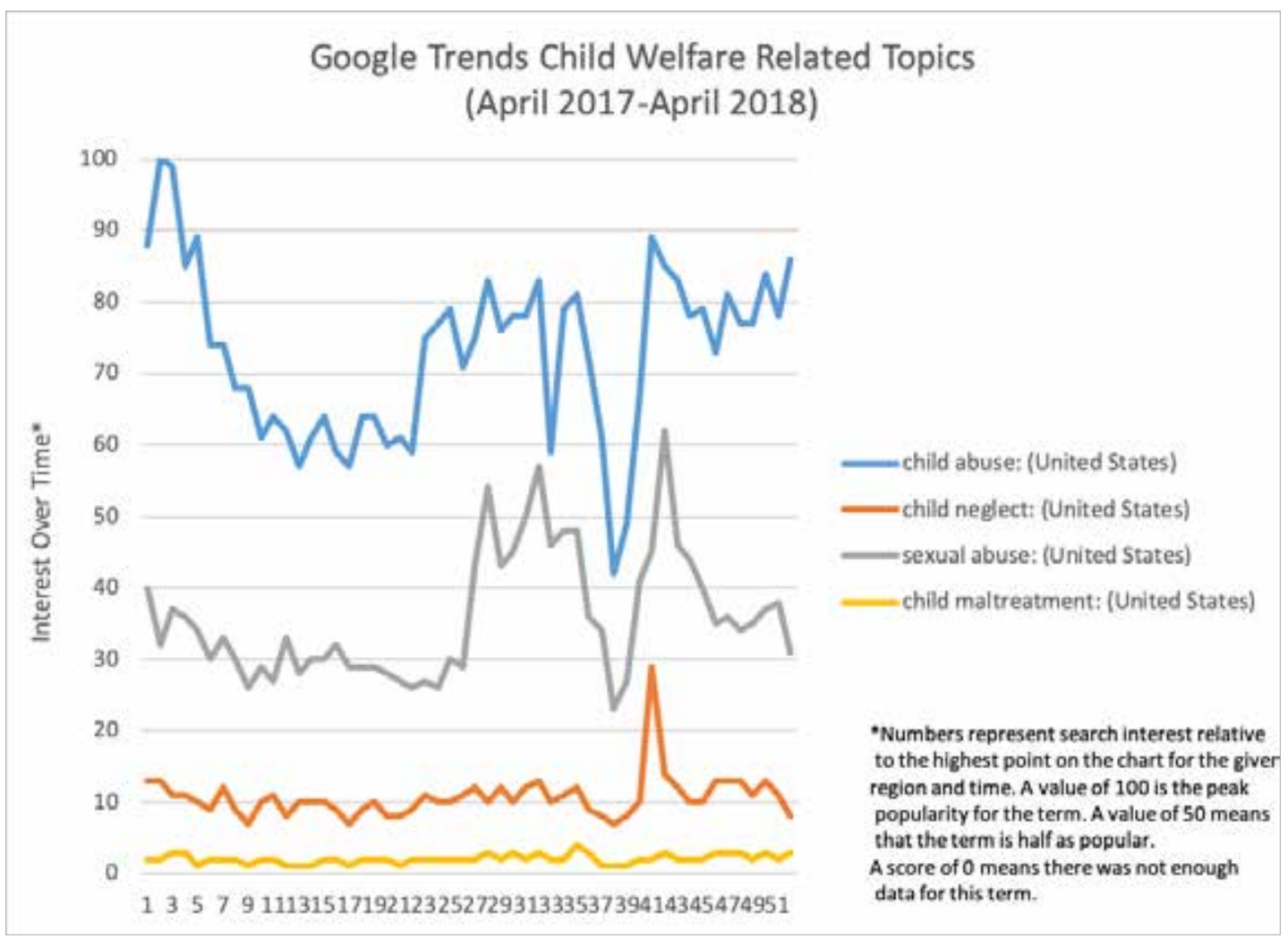

media and high risk behaviors (alcohol, substance use, smoking, and sexual behaviors) has found relationships between exposure on social media and increased likelihood of these behaviors (Brockman, Pumper, Christakis, \& Moreno, 2012; Moreno, Kacvinsky, Pumper, Wachowski, \& Whitehill, 2013; Moreno, 2012; Moreno et al., 2014). The study by Negriff and Valente (2018) adds to the research on social media use and high risk behaviors among adolescents involved in the child welfare system. Research has documented that child welfare youth are more willing to engage in high risk sexual behaviors. What is not as clear is if child maltreatment experiences also increase risky online social networking behaviors. Negriff and Valente (2018) article advances our understanding of the impact of social networking behaviors of a vulnerable child welfare population and its correlation to high risk sexual behaviors. These results may support the development of an online intervention, similar to Moreno and colleagues' (2009) intervention on MySpace, that specifically addresses high risk behaviors and provides adolescents, in child welfare or not, with awareness of their displays of high risk behaviors which could prevent or minimize engagement in high risk behaviors (Moreno et al., 2009).

Tablet and computer based technologies has been used in other areas of medicine, with adolescents, to facilitate disclosure of sensitive topics, specifically depression, sexual 
behaviors, and other sensitive topics (M. A. Moreno et al., n.d.). Wall, Jenney, and Walsh's (2018) article provides an overview of considerations and opportunities that are associated with data collection with vulnerable populations, including those who have experienced trauma and an innovative new tablet-based program to collect data on children's exposure to intimate partner violence. Researchers are constantly striving to balance the need to understand complex and potentially traumatic events, while also ensuring that children's voices are heard. The tablet application described by Wall and colleagues has the potential to minimize the difficulties associated with collecting data from children and adolescents while maximizing high quality and reliable data on traumatic experiences. This application still needs to be subjected to rigorous testing, (see ORBIT model; (Czajkowski et al., 2015) to determine its feasibility and eventually its efficacy.

\section{Conclusion}

Krazenberg's First Law (1986) perfectly summarizes where social science and computer science fields are intersecting: "environmental, social, and human consequences" are moving in directions that were possibly not anticipated when technology was originally developed. The intersection of social networking and research is also creating unique ethical challenges that have to be considered. Thomas Kuhn argued "Nevertheless, paradigm changes do cause scientists to see the world of their research engagements differently. Insofar as their only resource to that world is through what they see and do, we may want to say that after a revolution scientists are responding to a different world" (Kuhn, 1962, p. 110). Researchers and institutional review boards are faced with balancing protection of human subjects while also finding creative ways to collect data to inform our understanding of these intersections. It is exciting to see that child maltreatment and other violence-related social problems share unique features that create an opportunity for social media and technology-facilitated approaches to be used to better understand and disseminate information about these vulnerable populations.

\section{References}

Archibong, I. (2018). Facebook Platform Changes in Development. Retrieved April 8, 2018, from https:// developers.facebook.com/blog/post/2018/03/26/facebook-platform-changes/

boyd, danah. (2008). Taken Out of Context: American Teen Sociality in Networked Publics (SSRN Scholarly Paper No. ID 1344756). Rochester, NY: Social Science Research Network. Retrieved from https://papers.ssrn. com/abstract $=1344756$

Brockman, L. N., Pumper, M. A., Christakis, D. A., \& Moreno, M. A. (2012). Hookah's new popularity among US college students: a pilot study of the characteristics of hookah smokers and their Facebook displays. BMJ Open, 2(6), e001709-e001709. https://doi.org/10.1136/bmjopen-2012-001709

Czajkowski, S. M., Powell, L. H., Adler, N., Naar-King, S., Reynolds, K. D., Hunter, C. M., ... Charlson, M. E. (2015). From ideas to efficacy: The ORBIT model for developing behavioral treatments for chronic diseases. Health Psychology, 34(10), 971-982. https://doi.org/10.1037/hea0000161

Google Trends. (2018). Retrieved April 5, 2018, from /trends/explore

Griffiths, B. D. (2018, April 7). Cambridge Analytica whistleblower: Accessed Facebook profiles could exceed 87 million. Retrieved April 8, 2018, from https://politi.co/2GFk1tO 
Hawksey, M. (2018). TAGS. Retrieved April 8, 2018, from https://tags.hawksey.info/

Johansen, M. A., Berntsen, G. K. R., Schuster, T., Henriksen, E., \& Horsch, A. (2012). Electronic symptom reporting between patient and provider for improved health care service quality: a systematic review of randomized controlled trials. part 2: methodological quality and effects. Journal of Medical Internet Research, 14(5), e126. https://doi.org/10.2196/jmir.2216

Kranzberg, M. (1986). Technology and History: “Kranzberg's Laws.” Technology and Culture, 27(3), 544-560. https://doi.org/10.2307/3105385

Kuhn, T. S. (1962). The Structure of Scientific Revolutions (1st edition). Chicago: University of Chicago Press.

Moreno, M. A., Kacvinsky, L., Pumper, M., Wachowski, L., \& Whitehill, J. M. (n.d.). Associations Between Social Media Displays and Event-Specific Alcohol Consumption by College Students. Wisconsin Medical Journal, 112(6), 251-256.

Moreno, Megan A. (2012). Associations Between Displayed Alcohol References on Facebook and Problem Drinking Among College Students. Archives of Pediatrics \& Adolescent Medicine, 166(2), 157. https://doi. org/10.1001/archpediatrics.2011.180

Moreno, Megan A, D’Angelo, J., Kacvinsky, L. E., Kerr, B., Zhang, C., \& Eickhoff, J. (2014). Emergence and predictors of alcohol reference displays on Facebook during the first year of college. Computers in Human Behavior, 30, 87-94. https://doi.org/10.1016/j.chb.2013.07.060

Moreno, Megan A., Vanderstoep, A., Parks, M. R., Zimmerman, F. J., Kurth, A., \& Christakis, D. A. (2009). Reducing at-risk adolescents' display of risk behavior on a social networking web site: a randomized controlled pilot intervention trial. Archives of Pediatrics \& Adolescent Medicine, 163(1), 35-41. https://doi.org/10.1001/ archpediatrics.2008.502

Negriff, S., \& Valente, T. W. (2018). Structural characteristics of the online social networks of maltreated youth and offline sexual risk behavior. Child Abuse \& Neglect, 85, 209-219.

NIH Clinical Center: NIH Bench-to-Bedside Program. (2018). Retrieved April 9, 2018, from https://clinicalcenter. nih.gov/ccc/btb/

Paperny, D. M. (1997). Computerized health assessment and education for adolescent HIV and STD prevention in health care settings and schools. Health Education \& Behavior: The Official Publication of the Society for Public Health Education, 24(1), 54-70. https://doi.org/10.1177/109019819702400107

Schwab-Reese, L., Hovdestad, W., Tonmyr, L., \& Fluke, J. (2018). The potential use of social media and other internet-related data and communications for child maltreatment surveillance and epidemiological research: Scoping review and recommedations. Child Abuse \& Neglect, 85, 187-201.

Stevens, J., Kelleher, K. J., Gardner, W., Chisolm, D., McGeehan, J., Pajer, K., \& Buchanan, L. (2008). Trial of computerized screening for adolescent behavioral concerns. Pediatrics, 121(6), 1099-1105. https://doi. org/10.1542/peds.2007-1878

Timberg, C., Romm, T., \& Dwoskin, E. (2018, April 4). Facebook: 'Malicious actors' used its tools to discover identities and collect data on a massive global scale. Washington Post. Retrieved from https://www. washingtonpost.com/news/the-switch/wp/2018/04/04/facebook-said-the-personal-data-of-most-its-2billion-users-has-been-collected-and-shared-with-outsiders/

Wall, M., Jenney, A., \& Walsh, M. (2018). Conducting Evaluation Research with Children Exposed to Violence: How technological innovations in methodologies and data collection may enhance the process. Child Abuse \& Neglect, 85, 202-208.

Wearesocial.com. (2018, January 30). Digital in 2018: World's internet users pass the 4 billion mark. Retrieved May 9, 2018, from https://wearesocial.com/uk/blog/2018/01/global-digital-report-2018 